\title{
A method for purification, identification and validation of DNMT1 mRNA binding proteins
}

\author{
Alexander Unterberger*, Jérôme Torrisani* and Moshe Szyf*
}

\author{
These authors contributed equally to this manuscript. \\ \#Corresponding Author: Moshe Szyf, Ph.D., Department of Pharmacology and Therapeutics, McGill University, 3655, Sir William-0sler Promenade, \\ Montreal, QC, H3G 1Y6. Phone: (514) 398 7107; E-mail: moshe.szyf@mcgill.ca
}

Submitted: October 16, 2007; Revised: January 28, 2008; Accepted: January 31, 2008

Indexing terms: DNA (cytosine-5-)-methyltransferase 1; DNA Methylation; RNA-Binding Proteins

Abbreviations: AUF1, AU-rich element ARE:poly-(U)-binding/degradation factor; DNMT1, DNA methyltransferase 1

\section{ABSTRACT}

DNA methyltransferase 1 (DNMT1) is the enzyme responsible for the maintenance of DNA methylation patterns during cell division. DNMT1 expression is tightly regulated within the cell cycle. Our previous study showed that the binding of a protein with an apparent size of $\sim 40 \mathrm{kDa}$ on DNMT1 $3^{\prime}$-UTR triggered the destabilization of DNMT1 mRNA transcript during $G_{0} / G_{1}$ phase. Using RNA affinity capture with the 3'-UTR of DNMT1 mRNA and matrixassisted laser desorption-time of flight tandem mass spectrometry (MALDI-TOF-MS-MS) analysis, we isolated and identified AUF 1 (AU-rich element ARE:poly-(U)-binding/degradation factor) as the binding protein. We then validated the role of this protein in the destabilization of DNMT1 mRNA. In this report, we detail the different approaches used for the isolation, the identification of a RNA binding protein and the validation of its role.

\section{INTRODUCTION}

DNA methylation patterns are an essential component of the epigenome, which regulates gene expression. DNA Methyltransferase 1 (DNMT1) is the enzyme necessary for maintenance and propagation of DNA methylation patterns through the process of DNA replication. Previous studies have determined that levels of DNMT1 mRNA vary at different phases of the cell cycle with observed levels of DNMT1 at their highest in S phase, and lowest at $\mathrm{G}_{0} / \mathrm{G}_{1} \quad(1,2)$. Furthermore, it has been observed that expression of DNMT1 gene does not change through the cell cycle (3). Therefore it was proposed that a regulation element controlled the levels of DNMT1 mRNA in cycling cells. Detich et al. observed a $\sim 40 \mathrm{kDa}$ protein that bound the 3'-Untranslated Region (3'-UTR), which was shown to be essential for the cell cycle regulation of the mRNA, in a cell cycle dependent manner (4).

We determined the identity of this $\sim 40$ kDa DNMT1 3'UTR binding element through RNA affinity purification and protein sequencing by MALDI-TOF MS/MS, as AUF1
(5). AUF1, or AU-rich element (ARE)/poly-(U)binding/degradation factor, or heterogeneous nuclear ribonucleoprotein D (hnRNP D) $(6,7)$, has been previously shown to increase the destabilization of target mRNAs $(8,9)$, including p16, p21, Cyclin D1 and c-fos (10-12). Furthermore, we showed that AUF1 destabilizes DNMT1 mRNA in an exosomal dependent manner. Previous work has shown that AUF1 physically interacts with components of the exosome, a complex of $3^{\prime}-5^{\prime}$ exonucleases (13) and serves as a recruitment tool for the mRNA to the exosome. Finally regulation of DNMT1 mRNA by AUF1 occurred in a cell cycle dependent manner (5). Other members of the DNMT family, which include DNMT3a and DNMT3b, have been shown to vary in mRNA levels in a cell cycle dependent manner (2).

In this paper, we will discuss the methods used in our study to identify AUF1, as well as the techniques used to validate its regulation of DNMT1 mRNA. 


\section{MATERIALS AND METHODS}

\section{Purification of DNMT1 3'-UTR binding proteins}

\section{Biological samples}

Serum-starved pellets of HeLa cells were purchased from Cilbiotech (Belgium). A total number of $3.10^{9}$ cells were used for the purification and mass spectrometry identification. The cells were resuspended in $20 \mathrm{ml}$ of whole cell extraction buffer $(20 \mathrm{mM}$ Tris $\mathrm{HCl} ; 0.4 \mathrm{M} \mathrm{KCl}$; 20\% glycerol; $2 \mathrm{mM}$ DTT and Complete Protease Inhibitor $^{\circledR}$ (Roche Diagnostics)). The cells were incubated overnight at $-80^{\circ} \mathrm{C}$ and centrifuged twice at $13000 \mathrm{rpm}$ for 15 minutes. The supernatant was collected for purification.

\section{In vitro transcription of the substrate RNA}

Substrate RNAs were transcribed from pSP64-poly-(A) Control (Promega) and pSK 3'-UTR DNMT1-poly(A) (DNMT1 3'-UTR) plasmids using SP6 and T3 polymerases, respectively, using in vitro MEGAscript transcription kit (Ambion). DNMT1 3'-UTR sequence corresponds to the conserved region from the positions 5349 to 5405 of the DNMT1 mRNA (GenBank accession number NM001379.1) annealed with a poly-(A) sequence.

\section{RNA affinity chromatography}

Five hundred micrograms of in vitro-transcribed RNA (DNMT1 3'-UTR or Control) were hybridized with $500 \mathrm{mg}$ of oligo-(dT)-cellulose beads (Sigma-Aldrich) in incubation buffer (10 mM HEPES, $\mathrm{pH} 8.0 ; 3 \mathrm{mM} \mathrm{MgCl}_{2} ; 40$ $\mathrm{mM} \mathrm{KCl} ; 20 \%$ glycerol; $1 \mathrm{mM}$ DTT and Complete protease inhibitors ${ }^{\circledR}$ ) (final volume $5 \mathrm{ml}$ ). Whole-cell protein extracts $(1 \mathrm{mg})$ from serum-starved HeLa cells were incubated overnight at $4^{\circ} \mathrm{C}$ with either control or DNMT1 3'-UTR RNA probes annealed to oligo-(dT) beads in incubation buffer supplemented with tRNA. ProteinRNA-bead complexes were pelleted $(\sim 1 \mathrm{ml})$, and unbound proteins were eliminated by two washes $(20 \mathrm{ml})$ in the incubation buffer and five $20 \mathrm{ml}$-washes with washing buffer (10 mM HEPES, pH 8.0; $3 \mathrm{mM} \mathrm{MgCl}_{2} ; 40 \mathrm{mM} \mathrm{KCl}$; $20 \%$ glycerol; $1 \mathrm{mM}$ DTT; $500 \mathrm{mM} \mathrm{NaCl}$ and Complete protease inhibitors ${ }^{\circledR}$ ). Bound proteins were eluted by a step-wise gradient $(0.8 \mathrm{M}$ to $4.3 \mathrm{M} \mathrm{NaCl}$ ) (3 elutions of $1 \mathrm{ml}$ each). The fractions from each $\mathrm{NaCl}$ concentration were desalted and concentrated using Amicon Ultra-4 centrifugal filters (Millipore). Five microliters of the concentrated fraction were loaded onto $15 \%$ acrylamide gels and were verified for purification by silver staining using the BioRad silver staining kit (BioRad). Gels were stained with Coomassie Blue for mass spectrometry analysis. Coomassie Blue Staining was performed by fixing the gel (50\% methanol, $10 \%$ glacial acetic acid), staining for 20 minutes $(0.1 \%$ Coomassie Brilliant Blue R-250, 50\% methanol, 10\% glacial acetic acid). The gels were destained with destaining solution (40\% methanol, $10 \%$ glacial acetic acid), stored in 5\% glacial acetic acid. The gel was cut at the $\sim 40 \mathrm{kDa}$ band and analyzed by MALDI-TOF MS/MS

\section{Protein identification by MALDI-TOF MS/MS analysis}

MALDI-TOF MS/MS: DNMT1 3'-UTR-specific binding proteins were identified by comparing the DNMT1 $3{ }^{\prime}$ UTR and the control lanes. Gel slices were excised and digested with porcine trypsin on a MassPrep robotic workstation (Micromass). Tryptic peptides were analyzed on a QTrap 4000 ion trap mass spectrometer (Applied Biosystems). The tryptic peptides were applied to Picco Frit columns containing BioBasic $\mathrm{C}_{18}$ packing. Eluted peptides were electrosprayed as they exited the column, and doubly, triply, or quadruply charged ions were selected for passage into a collision cell. MS-MS data were analyzed by BioAnalyst 1.4 software (Applied Biosystems) and submitted to Mascot (Matrix Science) for identification by analysis against the NCBI non redundant database. MS-MS analyses were performed by the Genome Quebec Proteomic facility (Montreal, QuebecCanada).

Validation of AUF1 as a protein involvement in DNMT1 mRNA destabilization

\section{RNA-protein UV cross-linking}

HEK-293 cells were transiently transfected with expressing vectors containing cDNA for the 4 AUF1 isoforms (p37, p40, p42 and p45). Reaction mixture containing either $20 \mu \mathrm{g}$ of AUF1 transfectants or serumstarved Hela cell extracts, $\left[{ }^{32} \mathrm{P}\right]$-labelled DNMT1 3'-UTR or CT RNA probe (100 $000 \mathrm{cpm} /$ reaction) and $10 \mu \mathrm{g}$ of tRNA (as non specific inhibitor) were incubated for $1 \mathrm{~h}$ on ice in the following incubation buffer $10 \mathrm{mM}$ Hepes, $\mathrm{pH}$ 7.6; 3 $\mathrm{mM} \mathrm{MgCl} 2 ; 0 \mathrm{mM} \mathrm{KCl} ; 5 \%$ glycerol and $1 \mathrm{mM}$ DTT. The reactions were exposed to UV light for 10 minutes (254 $\mathrm{nm}$ ) in UV-Stratalinker (Stratagene). Free unbound probe was removed by treating the reaction with $1.5 \mu$ of RNAse A $(10 \mathrm{mg} / \mathrm{ml})$ and $1 \mu \mathrm{l}$ of RNAse T1 (1 Unit/ml) (Roche Diagnostics). Protein-RNA complexes were 
resolved on a $10 \%$ SDS-polyacrylamide gel buffer containing $10 \mathrm{mM}$ Tris- $\mathrm{HCl}$, pH 7.6; $100 \mathrm{mM} \mathrm{KOAc}$; electrophoresis. Gels were dried and RNA-protein complexes were visualized by exposition to PhosphorImager screen (Fujifilm imaging plate).

\section{RNA immunoprecipitation}

RNA immunoprecipitations were performed on HEK-293 or HEK-293 cells transfected with vectors containing FLAG tagged-AUF1 isoforms. FLAG-AUF1 immunoprecipitation reactions were performed using the anti FLAG-M2 agarose beads (Sigma-Aldrich). Briefly, whole cell extracts were incubated with M2 anti-FLAG antibody-agarose beads overnight, washed four times with extraction buffer and total RNAs were extracted using Trizol ${ }^{\circledR}$ reagent (Invitrogen). Immunoprecipitation of RNA bound to endogenous AUF1 immunoprecipitation was performed by cross-linking anti-AUF1 antibody (Upstate Biotechnology) to protein G-agarose beads using dimethylpimelimidate (Sigma-Aldrich). The immunoprecipitated RNA were purified by Trizol ${ }^{\circledR}$ RNA extraction method. The beads were resuspended in $1 \mathrm{ml}$ of Trizol $^{\circledR}$ and $200 \mu \mathrm{l}$ of chloroform. The upper phase was transferred to a microfuge containing $0.5 \mathrm{ml}$ of isopropanol and RNA was precipitated by centrifugation at maximum speed for 10 minutes. The RNA pellet was resuspended in $50 \mu \mathrm{l}$ of water and was subjected to DNAse I (Roche Diagnostics) treatment (10U in presence of $5 \mathrm{mM} \mathrm{MgCl}{ }_{2}$ ) overnight at $37^{\circ} \mathrm{C}$ ) to remove any trace of contaminating DNA. cDNAs were synthesized by treatment of RNAs with AMV reverse-transcriptase (Roche Diagnostics) following the manufacturer's recommendations. PCRs were performed as previously described (4) using the following primers: DNMT1 forward

(5'-ACCGCTTCTACTTCCTCGAGGCCTA-3'), DNMT1 reverse (5'-GTTGCAGTCCTCTGTGAACACTGTGG-3'), b-actin forward (5'-GTTGCTATCC AGGCTGTGCTA-3'), b-actin reverse (5'-GCGGATGTCCACGTCACACTT-3') (11), p21 forward (5'-GCCCAGTGGACAGCGAGCAG-3') and p21 reverse (5'-GCCGGC GTTTGGAGTGGTAGA-3'). PCR products were visualized after agarose gel electrophoresis and ethidium bromide staining.

\section{In vitro degradation assays}

RNA decay rates were assessed using the following protocol. Ten micrograms of whole extract of either AUF1 overexpressing cells or control cells and $250000 \mathrm{cpm}$ of in vitro synthesized DNMT1 3'-UTR or CT transcript were incubated for 0 to 30 minutes at $37^{\circ} \mathrm{C}$ in $25 \mu$ of reaction

$2 \mathrm{mM} \mathrm{Mg}(\mathrm{OAc})_{2} ; 2 \mathrm{mM}$ DTT; $0.1 \mathrm{mM}$ spermine (SigmaAldrich); 1 mM ATP; $0.4 \quad \mathrm{mM} \quad$ GTP; $10 \quad \mathrm{mM}$ phosphocreatine (Sigma-Aldrich); $1 \mu \mathrm{g}$ creatine

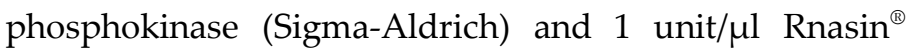
(Roche Diagnostics). The reaction was stopped by adding $400 \mu \mathrm{l}$ of stop reaction containing $10 \mathrm{mM}$ Tris- $\mathrm{HCl}, \mathrm{pH}$ 7.5; $350 \mathrm{mM} \mathrm{NaCl} ; 10 \mathrm{mM}$ EDTA; $\%$ SDS and $7 \mathrm{M}$ urea. After the addition of $20 \mu \mathrm{g}$ of tRNA (Sigma-Aldrich) as a carrier, the RNA was purified by phenol:chloroform (v/v) extraction. The aqueous phase was transferred into a tube containing 2 volumes of ethanol and was mixed by vortexing. Following 20 minutes incubation in a dry ice bath the RNA was precipitated by centrifugation at a microfuge for 10 minutes at maximum speed. The pellet was washed by adding ice-cold $70 \%$ ethanol and cetrifugation. The radioactive pellets were air dried and resuspended in water and denaturing RNA gel loading buffer (80\% formamide; $10 \mathrm{mM}$ EDTA; $1 \mathrm{mg} / \mathrm{ml}$ bromophenol blue (Sigma-Aldrich) and $1 \mathrm{mg} / \mathrm{ml}$ xylene cyanol (Sigma-Aldrich)). The samples were then electrophoresed on denaturing $7 \mathrm{M}$ urea-5\% (1:29 bis:acrylamide) polyacrylamide gels. The radioactive signals were visualized by autoradiography. The concentration of RNA at each time point was quantified by densitometry of the autoradiogram and is presented in the figure as the percentage of RNA remaining at each time point relative to the concentration of RNA at time 0 . The half-life of the different RNAs was calculated from the logarithmic decay plot.

\section{Biological consequences of AUF1 depletion}

\section{[3 ${ }^{3} \mathrm{H}$-Thymidine Incorporation}

The rate of DNA synthesis was determined $24 \mathrm{~h}$ after initiation of treatment with either control, AUF1 or DNMT1 siRNA treated cells by measuring $\left[{ }^{3} \mathrm{H}\right]$-thymidine incorporation into DNA following a 6-h pulse with 66 $\mu \mathrm{Ci} / \mathrm{ml}\left[{ }^{3} \mathrm{H}\right]$-thymidine. $\left[{ }^{3} \mathrm{H}\right]$-thymidine incorporation was assessed in triplicate of cells seeded at a density of 50000 cells per well of a six well dish. The remaining three wells of treated cells were counted to determine the overall number of cells. Pulsed cells were washed five times with phosphate buffer saline (PBS) and incubated in 10\% trichloroacetic acid at $4^{\circ} \mathrm{C}$ for $12 \mathrm{~h}$. Cells were washed twice with $5 \%$ trichloroacetic acid for $30 \mathrm{~min}$. The cells were lysed with $1 \%$ sodium dodecyl sulfate (SDS) in $1 \mathrm{~N}$ $\mathrm{NaOH}$, and the level of $\left[{ }^{3} \mathrm{H}\right]$-thymidine incorporation was 
measured in a liquid scintillation counter. The value of thymidine incorporation was normalized by the cell number for each treatment group.

\section{siRNA knock down of DNMT1 and AUF1}

To deplete DNMT1 or AUF1 we used siRNA knock down approach. Transfections of T24 cells were performed using Lipofectin $^{\circledR}$ transfection reagent (Invitrogen). Cells were seeded at a density of 300000 cells per $10 \mathrm{~cm}$-dish. siRNA oligonucleotides were purchased from Dharmacon. 24 hours after seeding, $100 \mathrm{nM}$ of siRNA oligonucleotide was incubated with $15 \mu \mathrm{l}$ Lipofectin $^{\circledR}$ and $4 \mathrm{ml}$ Opti-MEM serum-free media (Gibco-BRL) for 45 minutes at room temperature. After incubation the incubation period, cell medium was removed, cells were washed with PBS, and siRNA:Lipofection ${ }^{\circledR}$ :Opti-MEM mixture was added. The cells were incubated for 4 hours after which the mixture was removed and replaced with McCoy 5A medium (Gibco-BRL). The cells were incubated in regular medium for an additional 24 hours. The cells were harvested and the siRNA knock down effectiveness was validated by western blot analysis using antibodies for DNMT1 (NEB \#M0231S, at a dilution of 1:1000) and AUF1 (Abcam \#ab50692, at a dilution of 1:1000).

\section{Assay of DNA Methyltransferase activity}

The rate of DNA methyltransferase activity was determined in human fibroblasts cells (Coriell Cell Repository \#GM01887) 48 hours after treatment with either control or AUF1 siRNA. Transfections of fibroblasts were performed using Lipofectin $^{\circledR}$ as previously described. Proteins were extracted from these cells by freeze-thawing in lysis buffer ( $10 \mathrm{mM}$ Tris- $\mathrm{HCl}, \mathrm{pH}$ 7.6: 5 $\mathrm{mM} \mathrm{MgCl}_{2} ; 0.3 \mathrm{M} \mathrm{NaCl} ; 0.05 \%$ Tween $^{\circledR}$ and $10 \%$ Glycerol). The lysed cells were pelleted at $13000 \mathrm{rpm}$ at $4^{\circ} \mathrm{C}$ and the concentration of protein in the supernatants was measured using the BioRad protein assay reagent (Biorad). Ten micrograms of protein extract were incubated with a poly-dIdC template, [ $\left.{ }^{3} \mathrm{H}\right]$-S-Adenosyl Methionine (Sigma-Aldrich) in incubation buffer $(40 \mathrm{mM}$ Tris-HCl, pH 7.6; 50\% glycerol; 20 mM EDTA; $0.4 \mathrm{mM}$ PMSF and $60 \mathrm{mM} \mathrm{b}$-Mercaptoethanol) for 3 hours at $37^{\circ} \mathrm{C}$. The reactions were stopped by incubation at $65^{\circ} \mathrm{C}$ for 10 min, $750 \mu \mathrm{l}$ of $10 \%$ trichloroacetic acid (TCA) were added to the reactions, and the samples were incubated overnight at $4^{\circ} \mathrm{C}$. The reactions were filtered on GF/C filters, washed twice with (TCA) and dried. Filters were placed in scintillation mixture and activity was Szyf et al. A method for purification, identification and validation of DNMT1 mRNA binding proteins. www.biologicalprocedures.com

determined by scintillation counting. Reactions were performed in triplicate.

\section{Nearest Neighbour Analysis}

Levels of 5-methylcytosine in DNA extracted from cells transfected with either control or AUF1 siRNA were measured by nearest-neighbour analysis as described previously (14). Two micrograms of genomic DNA were incubated with $M b o I$ restriction enzyme (MBI-Fermentas) at $37^{\circ} \mathrm{C}$ overnight. The reaction was heat-inactivated at $65^{\circ} \mathrm{C}$ for 20 minutes and the DNA was recovered by ethanol precipitation. The MboI digested DNA was endlabeled with $10 \mu \mathrm{Ci}\left[\alpha{ }^{32} \mathrm{P}\right]$-dGTP (Amersham), $0.5 \mu \mathrm{l}$ Klenow enzyme (Roche Diagnostics) and $1.5 \mu \mathrm{l}$ of $10 \mathrm{X}$ Labeling buffer (Roche Diagnostics) at $15^{\circ} \mathrm{C}$ for 15 minutes. The reaction was stopped by addition of $2 \mu \mathrm{l}$ of $0.2 \mathrm{M}$ EDTA. Labeled DNA was purified by a Sephadex G50 spin column (Roche Diagnostics). $8 \mu$ l of DNA were digested with $1 \mu \mathrm{l}$ of Micrococcal Nuclease (Roche Diagnostics), $1 \mu \mathrm{l}$ of Spleen Phosphodiesterase (Roche Diagnostics) and $1 \mu \mathrm{l}$ of Micrococcal Nuclease buffer (250 $\mathrm{mM}$ Tris- $\mathrm{HCl}, \mathrm{pH} 7.4$ and $10 \mathrm{mM} \mathrm{CaCl}_{2}$ ) at $37{ }^{\circ} \mathrm{C}$ overnight. Digested DNA was separated by Thin-Layer Chromatography (TLC) on Polygram CEL 400 TLC sheets (Macherey-Nagel) in two dimensions, the first dimension solution consists of 66 volumes isobutyric acid: 18 volumes water: 3 volumes $30 \%$ ammonia solution, and the second dimension solution consists of 80 volumes saturated ammonium sulphate: 18 volumes $1 \mathrm{M}$ acetic acid: 2 volumes isopropanol. The intensity of 5methylcytosine and cytosine mononucleotide spots was measured using a PhosphorImager screen and the Image Quant image analysis program (GE Healthcare). Levels of unmethylated cytosine content are expressed as a percentage of [cytosine]/[cytosine + methylcytosine].

\section{RESULTS AND DISCUSSION}

Isolation and identification of AUF1 as a 3'-UTR DNMT1 mRNA-binding protein by RNA affinity chromatography and mass spectrometry

To identify the $\sim 40 \mathrm{kDa}$ protein which binds DNMT1 mRNA 3'-UTR specifically in $G_{0} / G_{1}$ phase of the cell cycle, we employed a RNA affinity chromatography approach. This technique use a specific RNA probe corresponding to the DNMT1 3'-UTR sequence to capture the candidate protein. Like other chromatography methods, RNA 
A

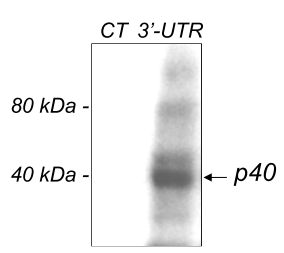

B

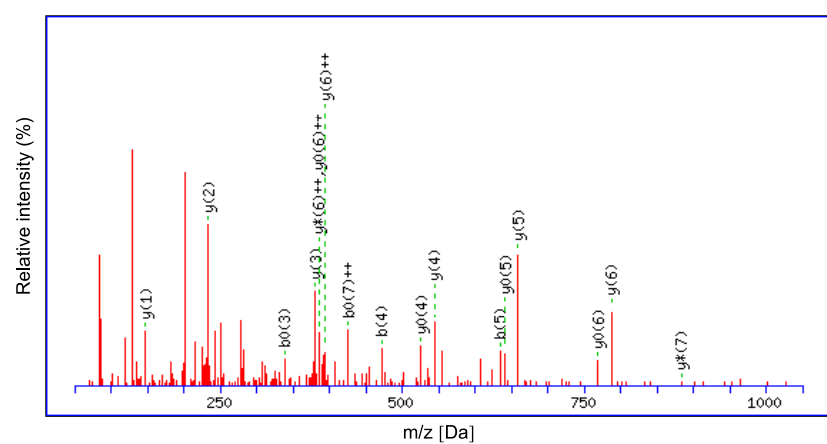

C

DNA-binding protein $=$ AUF1/hnRNP D

1 MAAGEQEGAM VAATQGAAAAAGSGPGPGAEPRLEAPKGSAESEGAKIDAS
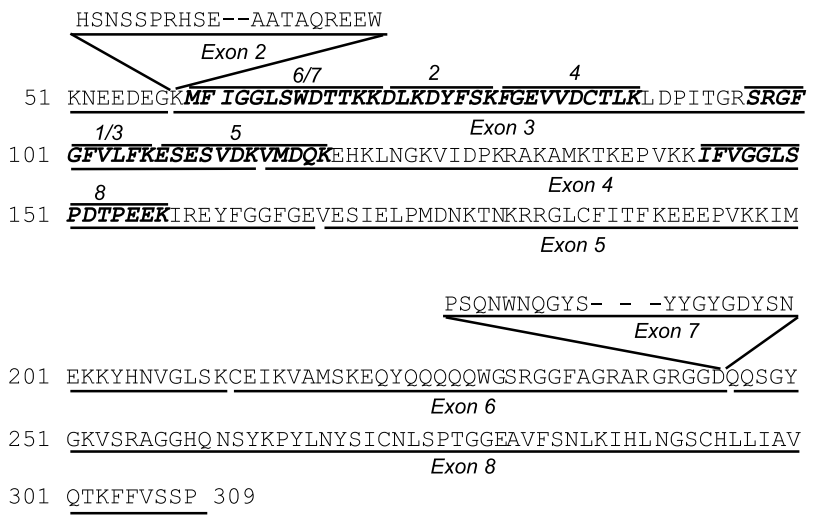

FIg. 1: Isolation and Identification of AUF1 as a 3'-UTR DNMT1 mRNA-binding protein by RNA affinity chromatography and mass spectrometry. (A) Cytoplasmic extract of serum-starved HeLa cells were incubated and UV cross-linked with a radioactive DNMT1 3'-UTR or Control RNA probe. The position of a $\sim 40 \mathrm{kDa}$ interacting protein is indicated by the arrow. (B) MS-MS spectrum of an identified peptide corresponding to the AUF1/hnRNP D sequence. (C) Peptide sequences of AUF1/hnRNP D isoforms. Peptide sequences identified by MALDI-TOF-MSMS are shown in boldface italic type.

affinity chromatography requires a large amount of starting biological material to isolate sufficient amounts of a single protein. Using sufficient amounts of starting material is essential for the success of the purification protocol. We started with one milligram of total protein extracted from Hela cells arrested in $G_{0} / G_{1}$ of the cell cycle. We first verified the presence of the $\sim 40 \mathrm{kDa}$ Szyf et al. A method for purification, identification and validation of DNMT1 mRNA binding proteins. www.biologicalprocedures.com interacting protein in our extract by RNA-protein UV cross-linking (Fig. 1A). The protein-RNA cross-linked extracts were incubated with $\left[{ }^{32} \mathrm{P}\right]$-labelled RNA probes corresponding to the DNMT1 $3^{\prime}$-UTR or to a random sequence $(\mathrm{CT})$.

The poly-(A) tailed-RNA probes were first annealed with oligo-(dT)-cellulose beads. The beads were extensively washed after hybridization to remove non-annealed RNA by resuspending the beads in incubation buffer followed by centrifugation. The washed RNA bait-cellulose beads $(\sim 1 \mathrm{ml})$ were incubated with one milligram of protein extract overnight at $4^{\circ} \mathrm{C}$ in an incubation buffer (see Material and Methods) supplemented with $5 \mu \mathrm{g}$ tRNA to reduce non-specific binding. Beads were washed with the incubation buffer two times followed by five washes with incubation buffer, containing $500 \mathrm{mM} \mathrm{NaCl}$, to remove non-specific interactions. Washes are essential for highquality purification and must be performed in a large volume (20 ml per $\sim 1 \mathrm{ml}$-bead pellet) for at least 15 minutes per wash. Proteins bound to the RNA bait were then eluted by step-wise salt gradient $(0.8 \mathrm{M}$ to $4.3 \mathrm{M}$ $\mathrm{NaCl} 0.5 \mathrm{ml}$ fractions). RNA-protein interactions are usually strong and required high salt concentrations to be disrupted. Due to their large volume the elutions were diluted and were therefore concentrated using Amicon Ultra-4 centrifugal filters (Millipore) and visualized by SDS-polyacrylamide electrophoresis followed by Coomassie blue staining.

A $\sim 40 \mathrm{kDa}$ protein in the $3.2 \mathrm{M}$ fraction, was found to interact specifically with DNMT1 3'-UTR RNA and not with the Control RNA bait. The band containing the protein of interest was excised and analyzed by MALDITOF-MS-MS. Since we were interested in the identification of a $\sim 40 \mathrm{kDa}$ interacting protein responsible for the destabilization of DNMT1 mRNA, we decided to excise the band containing the $\sim 40 \mathrm{kDa}$ protein. This technique could have been applied to analyse all the bands in order to identify all the RNA binding proteins interacting with DNMT1 3'-UTR. Eight sequenced peptides corresponding to the AUF1/hnRNP D protein which were common to all of the four isoforms were identified in the MS/MS analysis (Fig. 1B and C).

Other methods to isolate and identify RNA binding proteins have been developed. Many of them involve affinity chromatography using an in vitro transcribedRNA bait. They differ in strategy by coupling the RNA 
A

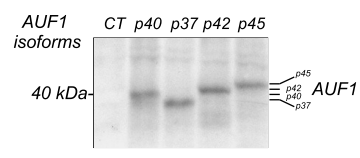

B
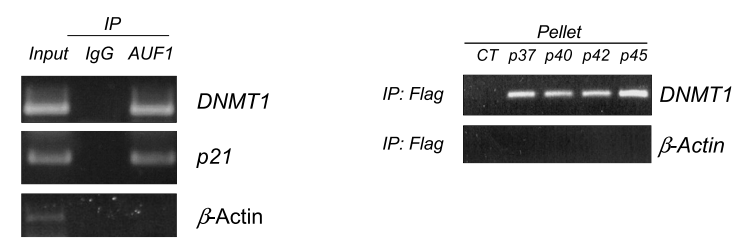

C
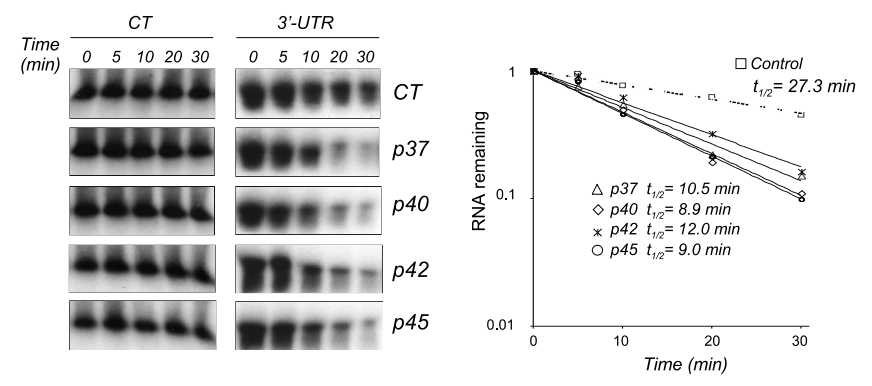

Fig. 2: Validation of AUF1 as a protein involved in DNMT1 mRNA destabllIzation. (A) RNA-protein UV cross-linking assay. Cytoplasmic extracts of HEK-293 cells transfected with cDNAs of the different AUF1 isoforms or a control vector (CT) were incubated with $\left.{ }^{32} \mathrm{P}\right]-$ labelled 3'-UTR DNMT1 (3'-UTR) and UV cross-linked. RNA-protein complexes were resolved by SDS-polyacrylamide gel electrophoresis and visualized by exposition to Phosphorlmager screen. (B) AUF1 protein was immunoprecipitated from HEK-293 extracts using anti-AUF1 antibody (left panel). Immunoprecipitation (IP) using rabbit immunoglobulin G (IgG) was performed as negative control. Immunoprecipitated RNAs, as well as RNA present in an aliquot of the initial extracts (Input), were extracted and subjected to reverse transcription.. Detection of DNMT1 and p21 mRNAs was performed by PCR. $\beta$-actin amplification was used as a negative control. HEK-293 cells were transfected with AUF1 cDNAs or a control vector (CT). Flag antibody-precipitated RNAs were extracted form the bead pellets (right panel). DNMT1 mRNAs were detected by RT-PCR and quantified. $\beta$-actin amplification was used as a negative control. (C) In vitro degradation assay. Cytoplasmic extracts from transfected HEK-293 cells (CT or AUF1 cDNAs) were incubated with radiolabeled DNMT1 3'UTR RNA transcript or control RNA probe for various lengths of time and electrophoresed. The signals were detected by autoradiography and quantified by densitometry. The half-lives were obtained by determining the time point at which $50 \%$ of the RNA had been degraded.

bait to agarose or sepharose beads. For example, several biotin-dUTP can be incorporated in the RNA by in vitro transcription or chemically added to an extremity (15). The bait is then coupled to the streptavidine-beads by one or several nucleotides. In our method, the annealing of the oligo-(dT)-beads with the poly-A tail of the RNA bait gave a better flexibility to the RNA bait which helped in obtaining a better capacity of interaction with RNA binding proteins. Recently developed, a technique makes use of a short, 45-nt RNA StreptoTag aptamer capable of Szyf et al. A method for purification, identification and validation of DNMT1 mRNA binding proteins. www.biologicalprocedures.com binding the antibiotic streptomycin (16). The RNA aptamer is linked in cis to the RNA sequence of interest in order to form a single hybrid RNA molecule which is in turn immobilised to a streptomycin-coupled sepharose column. This technique is efficient for high- and lowaffinity RNA binding proteins. However, the coupling of a 45-nt aptamer to our RNA bait could have generated an increase in non-specific interactions, due to similarities in size (54-nt)

Validation of AUF1 as a protein involvement in DNMT1 mRNA destabilization

\section{RNA-protein UV cross-linking}

After we identified the $\sim 40 \mathrm{kDa}$ protein interacting with DNMT1 3'-UTR as AUF1, we aimed to confirm that AUF1 interacts specifically with the 3'UTR of DNMT1 using several approaches. First, we verified the interaction of AUF1 with the DNMT1 3'-UTR by RNA-protein crosslinking (Fig. 2A). Whole cell extracts of HEK-293 AUF1 transfectants were incubated with $\left[{ }^{32} \mathrm{P}\right]$-labelled RNA probe corresponding to the DNMT1 3'-UTR conserved sequence or a control sequence. Successful visualization of the RNA-protein interaction is dependent on the quantity of AUF1 protein in the cell extracts. For this reason we chose HEK-293 cells which can be transfected by expression vectors at a high efficiency. This assay revealed that all four AUF1 isoforms can interact with DNMT1 3'UTR conserved sequence.

\section{RNA immunoprecipitation}

RNA immunoprecipitation technique detects the interaction of endogenous mRNA with the RNA binding protein in the cell. This technique is tightly dependent on the efficiency and the specificity of the interaction of the antibody to its target protein. We determined the specificity and efficiency of AUF1 and FLAG antibodies using Western blots and immunoprecipitation followed by Western blot with the antibody. This technique allowed us to detect the interaction of AUF1 with the endogenous DNMT1 mRNA in HEK-293 cells as well as p21 mRNA, which is a known AUF1 target (10) (Fig. 2B). The presence of the 3'UTR of DNMT1 in the AUF1 immunoprecipitate was determined by PCR with the relevant primers. We used b-actin mRNA as an AUF1 non-interacting mRNA negative control. The disadvantage of this technique is that it is qualitative and non-quantitative. We utilized the same technique with AUF1-tagged overexpressing cells to determine that the four AUF1 isoforms can interact with 
DNMT1 mRNA (Fig. 2B). This technique could easily be quantified using an antibody against endogenous AUF1 and real time quantitative PCR amplification.

\section{In vitro degradation assay}

The previous approaches are dedicated to the determination of RNA-protein interactions. In vitro degradation assay allowed us to examine the role of a protein in RNA destabilization. To validate the involvement of AUF1 isoforms in the destabilization of DNMT1 mRNA, we examined whether AUF1 altered the stability of DNMT1 mRNA. Using this approach, we showed that extracts obtained from HEK-293 cells ectopically expressing the AUF1 isoforms degraded DNMT1 3 '-UTR RNA at an accelerated rate (half-life $t_{1 / 2}$ : $10.5,8.9,12.0$ and $9.0 \mathrm{~min}$ ) relative to control vectortransfected cell extracts that contained markedly lower levels of endogenous AUF1 ( $\mathrm{t}_{1 / 2}: 27.3 \mathrm{~min}$ ) (Fig. 2C).

This technique contains technical difficulties that we should mention. Indeed, for short kinetic studies (30 sec to 1 minute) of highly unstable mRNAs, the main difficulty is to stop the reactions at the precise time point especially when multiple samples are processed simultaneously. We would advise the preparation of tubes containing stop reaction buffer in advance. A major technical barrier is proper homogenization of the emulsion during the phenol chloroform purification. Inattentive manipulation can generate inconclusive data. The presence of urea in the polyacrylamide gel wells sometimes can affect the migration, we advise a rapid rinse of the wells just before loading.

Several techniques to validate the interaction of a protein to a RNA sequence have been developed. RNA electrophoretic mobility shift assay (RNA-EMSA) is a common technique used to characterize protein:RNA interactions (17). However, the RNA:protein UV cross linking assay that we use here provides several advantages. Because the radioactive probe that is not bound or not protected by the UV cross linked protein is degraded by a RNAse A and T1 treatment. Only the protein(s) bound to the probe is (are) radioactively labelled. The electrophoretic migration in denaturing conditions permits an estimation of the apparent size of the interacting protein(s). Furthermore, the RNA probe:protein complexes can be electrotransfered onto nitrocellulose membrane to perform Western blot analysis in order to validate the identity of the protein present in the complex.

RNA immunoprecipitation is most appropriate technique to validate an interaction mRNA:protein in vivo. However, this technique requires antibodies with a high affinity and specificity for the proteins.

In vitro degradation assay is an accurate technique to measure the effects of a RNA interacting protein on the stability of specific mRNA (18). However, this technique requires the manipulation of radioactive probes and does not reflect a situation in a cellular context. Cell treatment by Actinomycin D (transcription blocker) can be an alternative to measure mRNA stability in vivo (5). After Actinomycin D treatment, the content of different mRNAs can be estimated by quantitative Real Time-PCR using specific primers. For example, their half lives in the presence of a RNA binding protein transiently expressed in the cells can be calculated.

\section{Biological consequences of an AUF1 depletion}

\section{$\left[{ }^{3} \mathrm{H}\right]$-Thymidine incorporation}

To determine the biological significance of the regulation of DNMT1 mRNA by AUF1 we assayed relevant biological endpoints related to the known cellular roles of DNMT1. We examined the effect of AUF1 depletion on DNA replication, as it has been previously shown that depletion of DNMT1 inhibits DNA replication (19). We performed a series of siRNA AUF1 depletions and examined the effect of AUF1 knock down on DNA replication and then tested whether DNMT1 is involved in the effect by concurrently depleting AUF1 and DNMT1. We used T24 human bladder carcinoma cells since we have previously used them to study the effects of DNMT1 depletion on DNA replication (5). Our siRNA was designed to target all four isoforms of AUF1, which effectively eliminated any potential redundancy from remaining AUF1 isoform. However, this strategy could not allow us to isolate which AUF1 isoform was essential in DNMT1 mRNA regulation. Utilizing the fact that incorporation of $\left[{ }^{3} \mathrm{H}\right]$-thymidine into DNA serves as an accurate indicator of the rate of DNA synthesis, we observed that upon depletion of AUF1, the subsequent increase in DNMT1 was associated with an increase in DNA synthesis, further supporting the concept that an increase in DNMT1 can affect DNA synthesis (19). To validate these claims, the elimination of DNMT1 by DNMT1 antisense in AUF1 siRNA treated cells returned 
A

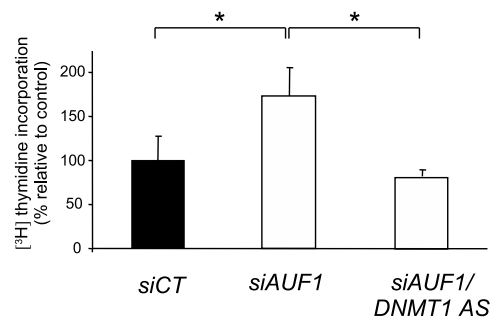

B

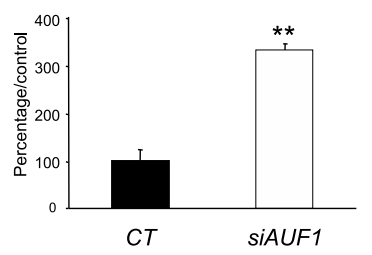

C

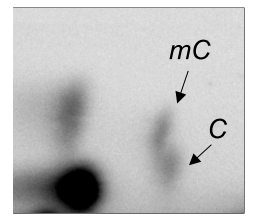

$C T$

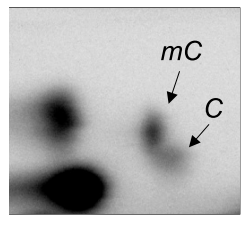

SiAUF1

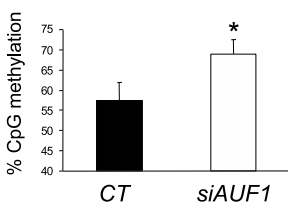

FIg . 3: Blologlcal consequences of AUF1 depletlon. (A) T24 cells were transfected with CT SiRNA (siCT), AUF1 siRNA (siAUF1), or a combination of AUF1 siRNA and DNMT1 antisense (DNMT1 AS) oligonucleotide. $\left[{ }^{3} \mathrm{H}\right]$-thymidine uptake was measured as described in Materials and Methods. The results are averages plus standard deviations from three independent experiments. Values that are statistically different (*) as tested by a Student's t test at a $p<0.05$ are indicated by the brackets. (B) Assay of DNA methyltransferase assay. DNA methyltransferase activity in AUF1 siRNA (siAUF1)- or CT siRNA (siCT)-transfected human fibroblasts was measured as described in Materials and Methods. The graph represents the averages plus the standard deviations from three different experiments. An asterisk indicates statistical significance as tested by Student $t$ test at a $p<0.05$. (C) The level of $C p G$ methylation in AUF1 siRNA (siAUF1)- or CT siRNA (siCT)-transfected human fibroblasts was measured by nearest-neighbour analysis. The graph represents the averages plus the standard deviations from three different experiments. An asterisk indicates statistical significance as tested by Student t test at a $p<0.05$.

the rate of DNA synthesis back to control levels (Fig. 3A). The major drawback of this technique is that it utilizes $\left[{ }^{3} \mathrm{H}\right]$-labelled thymidine and a dedicated radioactive facility would be required to perform any experiments. We would recommend that during the lysis step described in the methods the reaction mixture should be incubated at $37^{\circ} \mathrm{C}$ as the $\mathrm{SDS} / \mathrm{NaOH}$ solution precipitates at room temperature.

\section{Assay of DNA methyltransferase activity}

An essential criteria to demonstrate regulation of DNMT1 by AUF1 is to show that modulation of AUF1 would affect the biochemical activity of the DNMT1 enzyme. DNA methyltransferase activity assays were performed on nuclear extracts prepared from cells treated with either control or AUF1 siRNA. We observed that the elevation in DNMT1 levels induced by AUF1 siRNA depletion was accompanied by an increase in methyltransferase activity as expected (Fig. 3B).

The DNA methyltransferase assay requires radioactive labelled SAM and therefore necessitates a dedicated radioactive facility. When performing this assay a range of protein concentrations need to be taken to verify that we are working at the linear range of the assay. In addition, a time course has to be established to verify that the assay is measuring the initial rate. We used the concentration of 10 $\mu \mathrm{g}$ in our experiments; however we performed a range of concentrations ranging from 5 to $20 \mu \mathrm{g}$ to determine a linear dose response at this range of concentrations. Additionally, two background negative controls are used per assay. First, $\left[{ }^{3} \mathrm{H}\right]$-S-Adenosyl Methionine (SAM) alone with the reaction mixture but in the absence of protein and the second control is protein extract with $\left[{ }^{3} \mathrm{H}\right]-\mathrm{SAM}$ in absence of the DNA substrate poly-dIdC. The first control serves as a background value to subtract residual unincorporated SAM from all readings. The second control serves to subtract the substrate- independent methylation activity in the nuclear extract. The values of the first and second controls are subtracted from the readings for the complete reaction mixtures.

\section{Nearest neighbour analysis}

Following the determination of overall methyltransferase biochemical activity as a function of modulation of AUF1, we determined its effect on genomic DNA methylation (Fig. 3C). We utilized the nearest neighbour method to determine that AUF1 siRNA lead to a significant increase in CpG methylation. This method quantifies all the neighbours of the last $C$ in the sequence GATC in the genome; $\mathrm{CpC}, \mathrm{CpA}$. CpT, CpG and 5methylCpG. Thus, it gives a good representation of the global state of methylation. As stated previously, this technique requires a dedicated radioactivity facility suitable for working with $\left[{ }^{32} \mathrm{P}\right]$-isotopes. Furthermore this technique would require a chemical fumehood as the isobutyric acid used in the chromatography medium is quite volatile. It will require two chromatography glass tanks (Fisher Scientific) for each of the dimensions to increase the amount of runs that can be performed in a day. The technique involves certain 


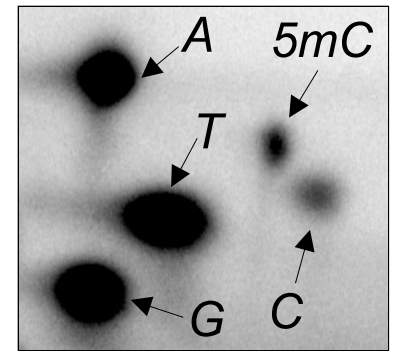

Fig. 4: Distribution of nucleotides after two-dimensional Thin-Layer Chromatography after Nearest Neighbour analysis.

challenges. First, the DNA should be treated with RNAse to eliminate contaminating RNA. To preserve the integrity of the DNA, the samples should not have been subjected to any mechanical shear or restriction enzymes. When the DNA is precipitated after MboI treatment great care should be taken to not disturb the DNA pellet as it is barely visible. Preparation of the Sephadex G-50 spin columns requires sterilized 8\% Sephadex G-50 in Tris- $\mathrm{HCl}$ EDTA as to prevent DNA contamination from any bacterial cultures. Bacteria are not methylated at the CG dinucleotides but contain a significantly higher frequency of CG dinucleotides than human DNA and can therefore seriously confound the results.

The thin-layer chromatographic (TLC) separation of nucleotides requires two TLC development tanks. The first dimensional tank solution should be prepared the day before the chromatography is performed to allow the isobutyric acid to equilibrate with the ammonia solution. The recommended size of the nylon-backed cellulose TLC plates is $10 \mathrm{~cm} \times 10 \mathrm{~cm}$ which allows for separate resolution of the cytosine and 5 methyl-Cytosine spots. Distribution of the labelled nucleotides can be seen in Fig 4 .

\section{Summary}

The methods described here can be utilized to identify and characterize proteins that can bind and regulate mRNA for genes expressing DNA methyltransferases. Using RNA affinity chromatography and mass spectrometry the binding protein was identified. Interaction of the protein, AUF1, with DNMT1 mRNA was further validated through RNA immunoprecipitations and UV-cross linking with RNA substrate. The biological role of the identified protein was seen through modulation of its levels by siRNA knockdown and assays were performed on the intended substrate, including DNA methyltransferase assays and nearest neighbour analysis for global DNA methylation content. Other tests included thymidine incorporation to determine the role of AUF1 on DNA replication.

\section{ACKNOWLEDGMENTS}

J.T was supported by a fellowship of the Institut National du Cancer (InCA-France). A.U was supported by the Canadian Institute of Health Research. The work was supported by a grant to MS from the National Cancer Institute of Canada and the Canadian Institutes of Health Research.

\section{REFERENCES}

1. Cervoni, N., Detich, N., Seo, S. B., Chakravarti, D., and Szyf, M. J Biol Chem 2002; 277(28): 25026-25031.

2. Robertson, K. D., Keyomarsi, K., Gonzales, F. A., Velicescu, M., and Jones, P. A. Nucleic Acids Res 2000; 28(10): 2108-2113.

3. Szyf, M., Bozovic, V., and Tanigawa, G. J Biol Chem 1991; 266(16): 10027-10030.

4. Detich, N., Ramchandani, S., and Szyf, M. J Biol Chem 2001; 276(27): 24881-24890.

5. Torrisani, J., Unterberger, A., Tendulkar, S. R., Shikimi, K., and Szyf, M. Mol Cell Biol 2007; 27(1): 395-410.

6. Brewer, G. Mol Cell Biol 1991; 11(5): 2460-2466.

7. Zhang, W., Wagner, B. J., Ehrenman, K., Schaefer, A. W., DeMaria, C. T., Crater, D., DeHaven, K., Long, L., and Brewer, G. Mol Cell Biol 1993; 13(12): 7652-7665.

8. Laroia, G., Cuesta, R., Brewer, G., and Schneider, R. J. Science 1999; 284(5413): 499-502.

9. Loflin, P., Chen, C. Y., and Shyu, A. B. Genes Dev 1999; 13(14): 1884-1897.

10. Chen, C. Y., Xu, N., and Shyu, A. B. Mol Cell Biol 2002; 22(20): 7268-7278.

11. Lal, A., Mazan-Mamczarz, K., Kawai, T., Yang, X., Martindale, J. L., and Gorospe, M. Embo J 2004; 23(15): 3092-3102.

12. Wang, W., Martindale, J. L., Yang, X., Chrest, F. J., and Gorospe, M. EMBO Rep 2005; 6(2): 158-164.

13. Chen, C. Y., Gherzi, R., Ong, S. E., Chan, E. L., Raijmakers, R., Pruijn, G. J., Stoecklin, G., Moroni, C., Mann, M., and Karin, M. Cell 2001; 107(4): 451-464.

14. Ramsahoye, B. H. Methods Mol Biol 2002; 200:9-15.

15. Tang, H., Xu, Y., and Wong-Staal, F. Virology 1997; 228(2): 333-339.

16. Dangerfield, J. A., Windbichler, N., Salmons, B., Gunzburg, W. H., and Schroder, R. Electrophoresis 2006; 
27(10): 1874-1877.

17. Garner, M. M., and Revzin, A. Nucleic Acids Res 1981; 9(13): 3047-3060.

18. Bose, S. K., Sengupta, T. K., Bandyopadhyay, S., and
Spicer, E. K. Biochem J 2006; 396(1): 99-107.

19. Knox, J. D., Araujo, F. D., Bigey, P., Slack, A. D., Price, G. B., Zannis-Hadjopoulos, M., and Szyf, M. J Biol Chem 2000; 275(24): 17986-17990.

\section{PROTOCOLS}

\section{RNA affinity chromatography}

1. Day 1. Lyse the cells in lysis buffer (see Materials and Methods) overnight at $-80^{\circ} \mathrm{C}$.

2. In vitro transcribed and purify the RNA bait using MEGAScript kit (Ambion).

3. Anneal $500 \mu \mathrm{g}$ of poly-(A) tailed-RNAs bait with $500 \mathrm{mg}$ of oligo-d(T) cellulose beads and wash the unbound RNA probes in excess.

4. Incubate the RNA bait-cellulose beads matrix with 1 milligram of protein extracts overnight at $4^{\circ} \mathrm{C}$ in the incubation buffer (see Materials and Methods).

5. Day 2. Wash twice with $20 \mathrm{ml}$ of incubation buffer and 5 times with $20 \mathrm{ml}$ of washing buffer (see Materials and Methods).

6. Elute the RNA interacting proteins with step-wise salt gradient buffers (see Materials and Methods).

7. Concentrate and analyse the fractions on SDS polyacrylamide gel electrophoresis and Coomassie staining.

8. Identify the protein(s) by MALDI-TOF-MS-MS analysis.

\section{RNA-protein UV cross-linking}

1. Mix $20 \mu \mathrm{g}$ of cell extracts with [ ${ }^{32} \mathrm{P}$ ]-labelled RNA probe (100 $000 \mathrm{cpm} /$ reaction), $10 \mu \mathrm{g}$ of tRNA in incubation buffer.

2. Incubate for $1 \mathrm{~h}$ on ice.

3. Expose to UV light ( $254 \mathrm{~nm})$.

4. Remove free unbound probe by RNAse A and T1 treatment.

5. Resolve RNA-protein complexes by $10 \%$ SDS-polyacrylamide electrophoresis.

6. Visualize after exposure to a PhosphoImager screen.

\section{RNA immunoprecipitation assay}

1. Lyse the cell in the appropriate lysis buffer.

2. Incubate cell extracts with anti Flag or anti AUF1 antibody coupled to agarose beads overnight at $4^{\circ} \mathrm{C}$.

3. Wash the pellets four times with a large volume of lysis buffer.

4. Extract RNA from the pellets using Trizol ${ }^{\circledR}$ reagent.

5. Perform a reverse transcription on the extracted RNAs.

6. Detect the putative target RNA by PCR amplification.

7. Visualize the PCR products by agarose gel electrophoresis followed by ethidium bromide.

8.

In vitro degradation assay

1. Lyse the cells in the appropriate lysis buffer.

2. Incubate $10 \mu \mathrm{g}$ of whole extracts with [ $\left.{ }^{32} \mathrm{P}\right]$-labelled RNA probe $(250000 \mathrm{cpm})$ in an incubation buffer (see Materials and Methods) for 0 to 30 minutes at $37^{\circ} \mathrm{C}$.

3. Stop the reaction at different time by adding $400 \mu \mathrm{l}$ of stop solution (see Materials and Methods).

4. After addition of tRNA as carrier, phenol:chloroform extraction and ethanol precipitation, radioactive pellets were resuspended in $10 \mu \mathrm{l}$ of water.

5. After denaturation in RNA gel loading buffer, the radioactive mixtures are resolved on urea-denaturing polyacrylamide gel electrophoresis.

6. Gels are dried and exposed to autoradiographic film. 
7. The concentration of RNA at each time point was quantified by densitometry of the autoradiogram.

\section{$\left[{ }^{3} \mathrm{H}\right]$-Thymidine incorporation assay}

1. Add $1 \mu \mathrm{Ci} / \mathrm{mL}$ media of $\left[{ }^{3} \mathrm{H}\right]$-thymidine to cells. Incubate for $5-6 \mathrm{~h}$.

2. Wash cells $4-5$ times with $2 \mathrm{ml}$ of PBS.

3. Incubate cells in $2 \mathrm{ml}$ of $10 \%$ TCA overnight at $4^{\circ} \mathrm{C}$.

4. Wash cells twice with $2 \mathrm{ml}$ of $5 \%$ TCA for 30 minutes each wash.

5. Lyse cells with $500 \mu \mathrm{l}$ of $1 \% \mathrm{SDS} / 1 \mathrm{~N} \mathrm{NaOH}$ solution for 10 minutes at $37^{\circ} \mathrm{C}$. Save lysate and repeat.

6. Place lysate in liquid scintillation counter tubes with $5 \mathrm{ml}$ of scintillation cocktail and read.

\section{Assay of DNA methyltransferase activity}

1. Incubate $10 \mu \mathrm{g}$ of protein extract with $3.7 \mu \mathrm{M}\left[{ }^{3} \mathrm{H}\right]$-S-adenosyl methionine in incubation buffer (40 $\mathrm{mM}$ Tris $\mathrm{HCl}, \mathrm{pH}$ 7.6; 50\% glycerol; $20 \mathrm{mM}$ EDTA; $0.4 \mathrm{mM}$ PMSF and $60 \mathrm{mM}$ b-mercaptoethanol) and $0.1 \mu \mathrm{g}$ poly-dIdC at $37^{\circ} \mathrm{C}$ for 3 hours.

2. Heat inactivate solutions at $65^{\circ} \mathrm{C}$ for $10 \mathrm{~min}$.

3. Add $750 \mu \mathrm{l}$ of $10 \%$ TCA solution and incubate at $4^{\circ} \mathrm{C}$ overnight.

4. Solutions are filtered on glass fiber filters and washed twice with $10 \%$ TCA.

5. Filters are dried, placed in $5 \mathrm{ml}$ scintillation cocktail and counted.

\section{Nearest neighbour analysis}

1. Digest $2 \mu \mathrm{g}$ of genomic DNA with 10 units of $\mathrm{MboI}$ overnight at $37^{\circ} \mathrm{C}$.

2. Heat inactivate $\mathrm{MboI}$ at $70^{\circ} \mathrm{C}$ for $20 \mathrm{~min}$.

3. Purify DNA by ethanol precipitation. Resuspend pellet in $10 \mu \mathrm{l}$ of water

4. Label digested DNA with $10 \mu \mathrm{Ci}\left[\alpha-{ }^{32} \mathrm{P}\right] \mathrm{dGTP}, 1.5 \mu \mathrm{l}$ of $10 \mathrm{X}$ labelling buffer (see Materials and Methods) and 0.5 $\mu \mathrm{l}$ of Klenow enzyme at $15^{\circ} \mathrm{C}$ for $15 \mathrm{~min}$.

5. Stop reaction with $2 \mu 1$ of $0.2 \mathrm{M}$ EDTA.

6. Purify DNA through a Sephadex G-50 spin column.

7. Digest $8 \mu \mathrm{l}$ of flow-through with $1 \mu \mathrm{l}$ of micrococcal nuclease, $1 \mu \mathrm{l}$ of spleen phosphodiesterase and $1 \mu \mathrm{l}$ of micrococcal nuclease buffer (see Materials and Methods) overnight at $37^{\circ} \mathrm{C}$.

8. Spot digestion solution at point of origin of TLC plate.

9. Run in $1^{\text {st }}$ dimension until the end of the plate. Dry plate under heat lamp.

10. Run in $2^{\text {nd }}$ dimension. Dry under heat lamp.

11. Visualize after exposure to a PhosphoImager screen. 